\title{
A Propósito do Artigo: "O Tratamento da Esclerose Múltipla com Natalizumab: Análise de uma Coorte Hospitalar"
}

\author{
Regarding the Article: "Multiple Sclerosis Treatment with Natalizumab: Analysis \\ of a Hospital-Based Cohort"
}

João de $S A^{1,2}$

Acta Med Port 2014 Jul-Aug;27(4):409-410

Palavras-chave: Anticorpos Monoclonais Humanizados/efeitos adversos; Esclerose Múltipla; Natalizumab; Leucoencefalopatia Multifocal Progressiva/induzida quimicamente.

Keywords: Multiple Sclerosis; Natalizumab; Treatment Outcome; Antibodies, Monoclonal, Humanized/ adverse effects; Leukoencephalopathy, Progressive Multifocal/chemically induced.

A esclerose múltipla (EM) é uma doença inflamatória crónica do sistema nervoso central (SNC) de etiologia desconhecida, embora seja largamente admitido que os mecanismos autoimunes têm, na sua patogénese, um papel determinante.

Classicamente a doença evolui por episódios neurológicos que aparecem ao longo do tempo e que traduzem a existência de focos de inflamação e desmielinização disseminados na substância branca do SNC - surtos de exacerbação da doença.

Até 1993, ano em que foi aprovada pela FDA a primeira formulação de IFN $\beta 1$-b $\left(\right.$ Betaseron ${ }^{\circledast} /$ Betaferon $^{\circledR}$ ) para o tratamento da doença, dispúnhamos penas de tratamento para os surtos e de terapêuticas sintomáticas para as sequelas. A partir desta data foi possível alterar o curso evolutivo da enfermidade, reduzindo a frequência de surtos em cerca de $30 \%$ e a atividade avaliada pela presença de novas lesões em ressonâncias magnéticas (RM) de crânio seriadas em cerca de $80 \%$.

Nos anos subsequentes foram testados e aprovadas outras formulações de IFN $\beta$ e, em 1996, era aprovado pela FDA o acetato de glatirâmero (Copaxone $\left.{ }^{\circledR}\right)$. Este armamentário terapêutico reproduzia em eficácia os resultados publicados no ensaio do Betaseron ${ }^{\circledR}$, sendo ponto assente que entrávamos numa nova era em que passávamos a ter disponíveis medicamentos capazes de alterar, ainda que de forma modesta, a história natural desta doença neurológica. A ênfase passou a ser colocada na terapêutica precoce da enfermidade, idealmente após o primeiro episódio clínico atribuído à doença, antes de haver prova clínica de disseminação temporal de lesões no SNC - síndroma clínico isolado $(\mathrm{SCl})$.

Em 2005 foi aprovado mais um medicamento para o tratamento da EM. Desta feita um anticorpo humanizado monoclonal denominado Natalizumab (Tysabri ${ }^{\circledR}$ ). Este anticorpo liga-se à sub-unidade $\alpha 4$ da integrina $\alpha 4 \beta 1$ (VLA-4), que é expressa na superfície de membrana dos linfócitos $T$ activados, impedindo a sua ligação a receptores mole- culares endoteliais de adesão (VCAM-1) e, portanto, interferindo com a migração destas células através da barreira hematoencefálica e com a sua entrada no SNC.

Administrada de 28 em 28 dias por via endovenosa, este medicamento apresentava uma eficácia ímpar nunca antes relatada em qualquer ensaio realizado em doentes com EM.

No estudo AFFIRM ${ }^{1}$ que durou dois anos, o fármaco foi testado contra placebo em 942 doentes com EM evoluindo por surtos, tendo sido encontrada uma redução de $68 \%$ da taxa anualizada de surtos tendo ainda sido significativamente reduzidas o número de lesões activas anuais em RM de crânio seriadas ( $92 \%$ no primeiro e segundo ano), bem como a progressão da incapacidade sustentada aos dois anos (42\%).

No ensaio clínico SENTINEL ${ }^{2}$ que envolveu 1171 doentes, o Natalizumab foi comparado com uma formulação de IFN $\beta-1$ a $\left(\right.$ Avonex $\left.^{\circledR}\right)$. Neste estudo, Natalizumab ou placebo foram associados a Avonex ${ }^{\circledR}$, ficando bem estabelecida a superior eficácia da associação. Destes ensaios clínicos emergia ainda o bom perfil de tolerabilidade do fármaco.

A aprovação do Natalizumab em 2005 pela FDA criava justificadas expectativas de se ter atingido um novo estádio no tratamento da EM alicerçado num novo patamar de eficácia.

Infelizmente, a comunidade científica foi abalada pelo relato de dois casos de leucoencefalopatia multifocal progressiva (LEMP) detectados no ensaio SENTINEL em doentes do braço de associação com Avonex ${ }^{\circledR}$. O laboratório retirou o fármaco do mercado quando, pouco tempo depois, foi reportado um novo caso de LEMP num ensaio com Natalizumab na doença de Crohn.

O reconhecimento da elevada eficácia do fármaco pela FDA, e posteriormente pela EMA, levou à sua reintrodução em 2006, em monoterapia, nos doentes nos quais as terapêuticas imunomoduladoras disponiveis haviam falhado, adoptando um programa estrito de farmacovigilância. Não sendo exactamente conhecidos os mecanismos segundo

1. Serviço de Neurologia. Hospital de Santa Maria. Centro Hospitalar Lisboa Norte. Lisboa. Portugal.

2. Faculdade de Medicina. Universidade de Lisboa. Lisboa. Portugal.

Recebido: 18 de Agosto de 2014 - Aceite: 18 de Agosto de 2014 | Copyright @ Ordem dos Médicos 2014 
os quais o Natalizumab activa o vírus JC, o acompanhamento dos doentes foi considerado elemento fundamental para procurar extrair elementos preditores e estratificadores de risco por forma a permitir uma criteriosa e mais segura utilização deste medicamento.

Foi criado na Dinamarca um centro de referência europeu para determinação da seropositividade para o vírus JC para onde passaram a ser enviados gratuitamente os soros dos doentes candidatos a terapêutica. A prevalência da positividade para o vírus JC é elevada rondando os $60 \%$. Com base nos elementos disponíveis e na análise dos casos de LEMP que foram sendo diagnosticados, foi possível construir um algoritmo de risco. É reconhecido que o risco de um doente com EM desenvolver LEMP depende da positividade para o vírus JC (a técnica foi recentemente modificada aumentando a sensibilidade e diminuído os falsos negativos), do tempo de exposição ao fármaco (aumenta acima dos dois anos) e da terapêutica prévia com imunossupressores.

Até fevereiro de 2013 foram confirmados mundialmente 331 casos de LEMP, dos quais três em Portugal e 76 óbitos. Nos doentes seronegativos e nos quais a seronegatividade persiste ao longo do tempo (preconiza-se testar nesta população a seropositividade todos os seis meses), o risco de LEMP é desprezível (<0,09/1000) e o fármaco pode ser usado com toda a segurança. Nos doentes seropositivos para $\mathrm{JC}$, tratados há mais de 24 meses com Natalizumab e sem terapêuticas imunossupressoras prévias o risco de LEMP é intermédio (3,7-5,6/ 1000), requerendo nesta população uma avaliação partilhada de risco e uma vigilância clínica e imagiológica apertadas (RM de crânio semestrais). Nos doentes seropositivos para JC, previamente tratados com imunossupressores, acima dos 24 meses de tratamento com Natalizumab, o risco de LEMP é muito elevado (8,3-14,5/ 1000) e, nesta população, o fármaco deverá ser

\section{REFERÊNCIAS}

1. Polman $\mathrm{CH}$, O’Connor PW, Havrdova E, Hutchinson M, Kappos L, Miller $\mathrm{DH}$, et al. A randomized, placebo-controlled trial of natalizumab for relapsing multiple sclerosis. N Engl J Med. 2006;354:899-910.

2. Rudick RA, Stuart WH, Calabresi PA, Confavreux C, Galetta SL, Radue EW, et al. Natalizumab plus interferon beta-1a for relapsing multiple sclerosis. N Engl J Med. 2006;354:911-23.

3. Fernandez $\mathrm{O}$. Best practice in the use of natalizumab in multiple sclero- descontinuado. ${ }^{3}$ Mais recentemente, procura-se introduzir neste algoritmo de estratificação de risco o título serológico de positividade para o vírus JC.

Vários têm sido os estudos relatando a experiência clínica do dia-a-dia com o tratamento com Natalizumab. Apesar das limitações metodológicas, todos eles são unânimes em relatar uma elevada eficácia na redução da actividade da doença.

$\mathrm{O}$ artigo de Carvalho et $\mathrm{al}^{4}$ reporta a experiência com o Natalizumab na consulta de EM do Centro Hospitalar de São João no Porto entre 2007 e 2013. Tem as limitações que os próprios autores reconhecem da recolha retrospectiva de dados, aliada ao facto das características dos doentes recrutados ir variando ao longo deste longo período de tempo de acordo com o estado da arte sobre o conhecimento da estratificação de risco.

Esta coorte de doentes integra maioritariamente uma série nacional mais alargada de doentes recrutados em vários centros portugueses (oito centros) fazendo parte do estudo TOP (Tysabri ${ }^{\circledR}$ Observational Program), não tendo sido encontradas diferenças importantes entre os doentes dos diferentes centros nacionais e entre estes e os seus congéneres internacionais, ${ }^{5}$ reforçando o conceito da elevada eficácia desta medicação aliada à boa tolerância e a um adequado perfil de segurança, uma vez minimizado o risco de LEMP.

Apesar de terem sido entretanto aprovadas novas formulações para o tratamento da EM evoluindo por surtos, o Natalizumab continua a ser o medicamento com maior eficácia no controlo da fase inflamatória da doença. Esperamos que os próximos meses nos tragam ensinamentos que permitam refinar o algoritmo de estratificação de risco, para que um maior número de doentes portadores de EM possa ser tratado de forma segura.

sis. Ther Adv Neurol Disord. 2013;6:69-79.

4. Carvalho AT, Abreu P, Sá MJ. Multiple sclerosis treatment with natalizumab - analysis of a hospital-based cohort. Acta Med Port. 2014;27:437-43.

5. Butzkueven H, Kappos L, Pellegrini F, Trojano M, Wiendl H, Patel RN, et al. Efficacy and safety of natalizumab in multiple sclerosis: interim observational programme results. J Neurol, Neurosurg psychiatry. 2014 Feb 14. 


\section{A Propósito do Artigo: "O Tratamento da Esclerose Múltipla com Natalizumab: Análise de uma Coorte Hospitalar" \\ Acta Med Port 2014:27:409-410}

Publicado pela Acta Médica Portuguesa, a Revista Científica da Ordem dos Médicos

Av. Almirante Gago Coutinho, 151

1749-084 Lisboa, Portugal.

Tel: +351218428215

E-mail: submissao@actamedicaportuguesa.com

www.actamedicaportuguesa.com

ISSN:0870-399X | e-ISSN: 1646-0758

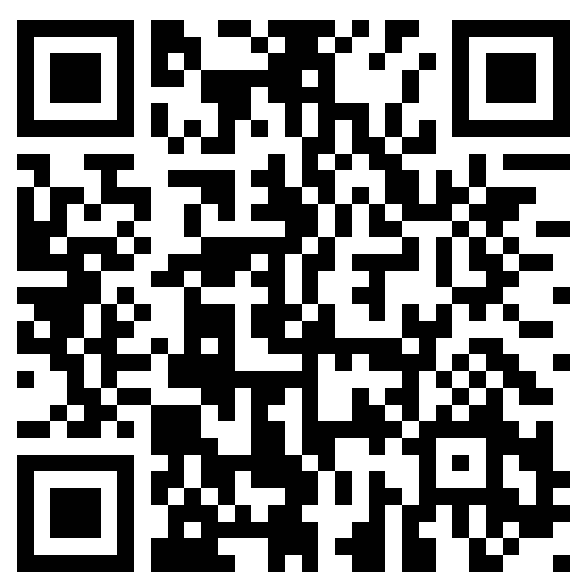

